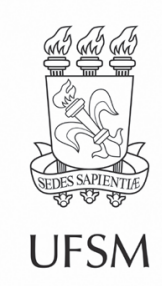

\title{
Artigos
}

\section{Caracterização florística e estrutural da vegetação arbórea em um trecho de Floresta Estacional Decidual, RS, Brasil}

\author{
Floristic and structural characterization of tree vegetation in a Deciduous \\ Seasonal Forest sector, RS state, Brazil
}

\section{Francieli de Fátima Missio ${ }^{\oplus}$, Solon Jonas Longhi ${ }^{\oplus}$, Matheus Degrandi Gazzola' ${ }^{\oplus}$, Marina Scheuer ${ }^{\oplus}$, Rodrigo da Silva Pinto $^{\oplus}$, Lutero Lerner $^{\top}$, $^{\circ}$ Diego Cella Cassol' ${ }^{\oplus}$, Gabriel Angostini Orso ${ }^{\oplus}$, Mauricio Stangarlin $^{\oplus}$}

Universidade Federal de Santa Maria, Santa Maria, RS, Brasil

\section{RESUMO}

O objetivo do estudo foi avaliar a composição florística e estrutural em um trecho de floresta secundária, no município de Dona Francisca - RS. Foram instaladas 50 parcelas permanentes de dimensão $10 \times 20$ m, de modo sistemático, distanciadas $10 \mathrm{~m}$ entre si e $40 \mathrm{~m}$ entre faixas, totalizando 1 ha. Foram amostrados todos os indivíduos que apresentassem CAP $\geq 15,7 \mathrm{~cm}$ e calculado os estimadores fitossociológicos. Foi realizada a curva de acumulação de espécie para verificar a suficiência amostral. Para o cálculo de diversidade e dominância, utilizou-se o Índice de Shannon $\left(\mathrm{H}^{\prime}\right)$ e Equabilidade de Pielou (J'). Para a riqueza potencial utilizaram-se os estimadores não paramétricos Jackknife. Avaliou-se a composição florística e estrutural por meio da Análise de Correspondência Distendida (DCA). Verificou-se, também, a distribuição diamétrica e hipsométrica da comunidade arbórea, e para as espécies, com valor de importância acima de $5 \%$, a distribuição em classes de DAP. As análises estatísticas foram realizadas no programa R. Foram identificadas 65 espécies arbóreas e arbustivas com 2.045 indivíduos distribuídas em 31 famílias botânicas. As espécies com valor de importância acima de 5\% foram Casearia sylvestris $(14,04 \%)$, Nectandra lanceolata (12,86\%), Cupania vernalis (9,57\%), Guarea macrophylla (7,29 \%) e Ocotea puberula (5,07 \%). Os valores para a diversidade e dominância foram, respectivamente, de 2,91 nats. ind $^{-1}$ e 0,69, indicando que a área possui baixa diversidade e dominância de poucas espécies. Pela DCA é possível verificar que as parcelas estão distribuídas homogeneamente no trecho florestal. A distribuição diamétrica representou o esperado para a comunidade arbórea com tendência ao J-invertido e a maioria das árvores apresentou altura concentrada no estrato intermediário da floresta. Das cinco espécies analisadas, apenas Nectandra lanceolata e Ocotea puberula não apresentaram curva exponencial negativa. Foi possível observar que há um predomínio de indivíduos nas primeiras classes de DAP e altura, o que caracteriza a resiliência da área após distúrbio. Ainda, indica as flutuações e estabilidade das espécies, na sucessão ecológica, de uma floresta em estágio intermediário de regeneração.

Palavras-chave: Estimadores fitossociológicos; Sucessão secundária; Método de Spiegel 


\section{ABSTRACT}

The objective of the study was to evaluate the floristic and structural composition of an area located in a section of secondary Forest, in the municipality of Dona Francisca, RS state. To do so, 50 permanent plots with a dimension of $10 \times 20 \mathrm{~m}\left(200 \mathrm{~m}^{2}\right)$ were installed in a systematic way, $10 \mathrm{~m}$ apart and 40 $\mathrm{m}$ between tracks, totaling 1 ha. All individuals with CAP $\geq 15.7 \mathrm{~cm}$ were identified and sampled and the phytosociological estimators were calculated. The species accumulation curve was used to verify the sample adequacy. For the calculation of diversity and dominance estimators, the Shannon Index $\left(\mathrm{H}^{\prime}\right)$ and Pielou Equability $\left(\mathrm{J}^{\prime}\right)$ were used. Subsequently, the floristic and structural composition was evaluated through the Distributed Correspondence Analysis (DCA). It was also verified the diameter and histopic distribution of the tree community, and for the species, with importance value above $5 \%$, the distribution in classes of DAP. Statistical analyzes were performed in the R program. 65 tree and shrub species were identified with 2,045 individuals distributed in 31 botanical families. The species with a value of importance above 5\% were Casearia sylvestris (14, $04 \%)$, Nectandra lanceolata (12, $86 \%)$, Cupania vernalis (9, $57 \%)$, Guarea macrophylla (7,29 \%) and Ocotea puberula $(5.07 \%)$. The values for diversity and dominance were, respectively, 2.91 nats.ind $^{-1}$ and 0.69 , indicating that the area has low diversity and dominance of few species and that by DCA it is possible to verify that the plots are homogeneously distributed in the forest. The diameter distribution represented the expected behavior for the arboreal community with J-inverted tendency and the majority of the trees presented height concentrated in the middle stratum of the forest. Only Nectandra lanceolata and Ocotea puberula did not present negative exponential curve from the five species analyzed. It was possible to observe the mosaic of tree species distributed in the forest section. In addition, there is a predominance of individuals in the first classes of DBH and height, which characterizes the resilience of the area after the disturbance and its capacity for natural recovery. It also indicates the fluctuations and stability of species in ecological succession of a forest in an intermediate stage of regeneration.

Keywords: Phytosociological estimators; Secondary vegetation; Spiegel method

\section{INTRODUÇÃO}

A Floresta Estacional Decidual representa uma grande diversidade de espécies que se distribuem pelo estado, compondo a caracterização florística dos 553 tipos de arvoretas, árvores e palmeiras da fisionomia vegetal (SOBRAL et al., 2013). Porém, como consequência da fragmentação, a mesma tipologia está fortemente associada ao predomínio da atividade agropecuária, seguida do corte raso ou seletivo da vegetação. Atualmente, encontra-se em pequenos remanescentes que resultaram do abandono devido à dificuldade de acesso, principalmente nas áreas mais íngremes do relevo no rebordo do Planalto Meridional. Aliado a isso, ocorreu perda de espécies que compõem a fisionomia e composição florística. 
Decorrente desse processo de mudança da paisagem natural da tipologia no estado, inúmeros trabalhos foram realizados descrevendo sua atual composição florística e capacidade de resiliência da vegetação secundária (SCHUMACHER et al., 2011). Para isso, são indispensáveis os estimadores de riqueza, abundância e diversidade como parâmetros no diagnóstico florístico e estrutural da composição de espécies, que são fundamentais para compreender o processo de dinâmica florestal (GASTAUER; MEIRA-NETO, 2015).

Por sua vez, considerando a dinâmica florestal, o novo paradigma ecológico trouxe a dispensa dos preceitos clássicos da sucessão, a qual era vigente a partir de estudo da composição e estrutura das florestas maduras na definição de apenas um clímax único para todos os ecossistemas florestais (PICKETT; OSFELD, 1994; COOK, 1996; MARTINS, 2012). Nesse caso, em áreas que sofreram distúrbios antrópicos, é essencial compreender que as mesmas tendem a apresentar múltiplos estágios sucessionais até a sua reestruturação. Desse modo, a partir dos múltiplos caminhos é que deverá ser considerado o mosaico estabelecido pela fisionomia predominante da vegetação (GANDOLF; MARTINS; RODRIGUES, 2007).

Nesse sentido, faz-se de grande importância os estudos com enfoque na vegetação arbórea estabelecida em áreas que sofreram algum distúrbio, assim como a análise dos processos ecológicos que definem sua estrutura. A floresta vai responder de maneira diferente ao estágio de sucessão em que se dispõe, de acordo com as características ou adaptações ecológicas predominantes naquele mesmo ambiente.

Considerando o exposto acima, o presente estudo teve como objetivo estudar a fisionomia estabelecida em uma área de encosta de Floresta Estacional Decidual na região central do estado do Rio Grande do Sul, após corte raso, visando analisar sua composição e estrutura para entender o processo de sucessão da vegetação modificada pela interferência antrópica. 


\section{MATERIAL E MÉTODO}

O presente estudo foi realizado em um trecho de Floresta Estacional Decidual, considerado secundário em estágio de regeneração médio a avançado, segundo a classificação do Conama (BRASIL, 1994), no município de Dona Francisca, nas

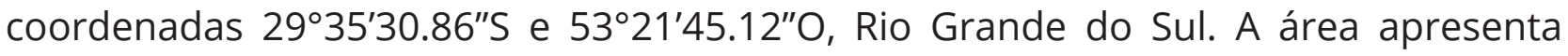
aproximadamente 7 ha, com altitude média de $171 \mathrm{~m}$. O clima predominante da região, segundo a classificação de Köppen (1936), é considerado do tipo Cfa - Subtropical úmido, com duas estações do ano bem definidas, o inverno com temperatura máxima de $18^{\circ} \mathrm{C}$ e verão com temperaturas superiores a $22^{\circ} \mathrm{C}$ e chuvas bem distribuídas o ano todo.

No entorno do trecho florestal, há o predomínio da agricultura de subsistência, sendo a área de estudo pertencente a uma propriedade particular. O histórico de degradação foi, principalmente, no passado, quando ocorreu o corte raso da vegetação para a agricultura. Após, houve o abandono da área, possibilitando o restabelecimento da vegetação nativa.

O trecho possui uma heterogeneidade ambiental representada por nascentes, curso d'água, topografia com relevo ondulado a forte ondulado. Os solos da região são classificados em Argissolos e Cambissolos associados a Neossolos, bem como um compartimento geomórfico classificado como patamar descontínuo (PEDRON et al., 2007; PEDRON; DALMOLIN, 2011).

Para o levantamento florístico e estudo fitossociológico, foram instaladas 50 parcelas permanentes em 10 faixas paralelas no sentido base ao topo da encosta, de dimensões $10 \times 20 \mathrm{~m}\left(200 \mathrm{~m}^{2}\right)$. As parcelas foram alocadas seguindo o padrão sistemático, sendo distanciadas $10 \mathrm{~m}$ entre si e $40 \mathrm{~m}$ entre as faixas, amostrando 1 ha de floresta (Figura 1).

$\mathrm{Na}$ amostragem, todos os indivíduos arbóreos e arbustivos com CAP (circunferência a altura do peito, medido a 1,30 m do solo) maior ou igual a 15,7 cm 
foram marcados com placas de alumínio numeradas em ordinais crescentes. Desses indivíduos mensurou-se, com auxílio de uma fita métrica, a circunferência para posterior transformação do DAP (diâmetro a altura do peito) e a altura foi estimada com auxílio de uma régua graduada em metros. Os indivíduos que apresentavam bifurcação abaixo de 1,30 m, incluídos na amostragem, foram aqueles cujos diâmetros obtidos pela raiz quadrada da soma do quadrado das circunferências apresentassem circunferência maior ou igual a $15,7 \mathrm{~cm}$.

Figura 1 - Localização da área de estudo e disposição das 50 parcelas em 10 faixas paralelas no trecho de Floresta Estacional Decidual, RS, Brasil

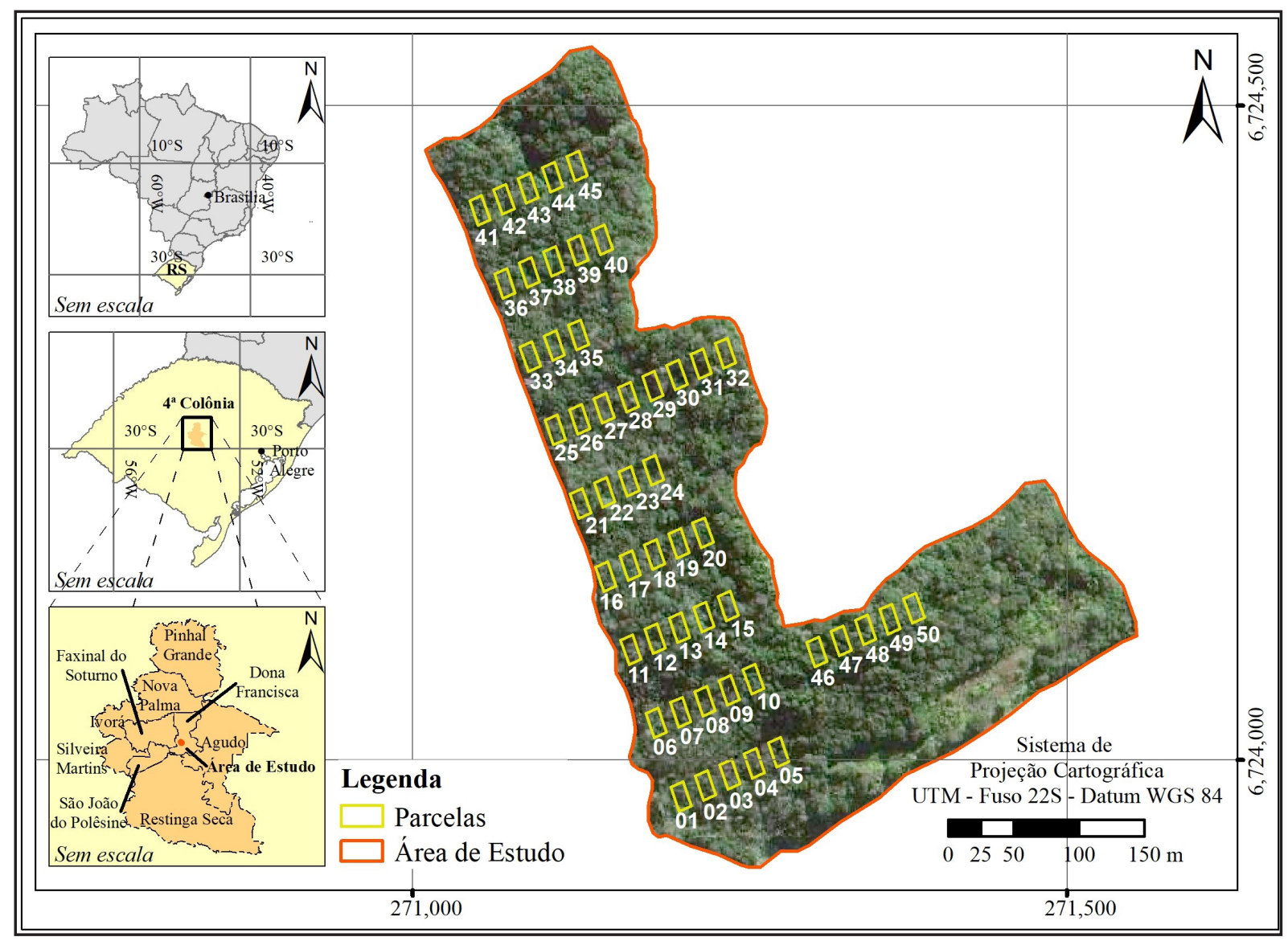

Fonte: Autores (2020)

As espécies foram identificadas in loco e quando não foi possível, coletou-se material botânico e este foi encaminhado à consulta de especialistas ou comparado à 
literatura de Lorenzi et al. (2006) e Sobral et al. (2013), no Herbário do Departamento de Ciências Florestais (HDCF) na Universidade Federal de Santa Maria. As espécies foram identificadas em nível de família, sendo classificadas de acordo com a APG IV (ANGIOSPERM PHYLOGENY GROUP, 2016) e o nome científico atualizado conforme a Lista de Espécies da Flora do Brasil (JARDIM BOTÂNICO DO RIO DE JANEIRO, 2016). Quanto à lista de espécies identificadas neste estudo, as mesmas não foram depositadas na coleção do herbário HDCF, por carecerem de material fértil na época do levantamento florístico.

Com a finalidade de verificar a suficiência amostral, foi elaborada a curva de acumulação de espécies, a partir de uma matriz formada pela densidade das espécies por parcela, utilizando a técnica de aleatorização com 1.000 interações. Para estimar a riqueza potencial de toda a área, utilizaram-se os estimadores não paramétricos Jackknife de primeira e segunda ordem. O estimador Jackknife1 estima a riqueza pelo número de espécies que ocorrem em uma parcela, ao passo que o Jackknife2 considera a riqueza total do número de espécies entre duas parcelas (BURNHAM; OVERTON,1978; HELTSHE; FORRESTOR, 1983).

Foi determinada a estrutura horizontal da comunidade arbórea pelo cálculo dos estimadores clássicos da fitossociologia: densidade absoluta, densidade relativa, dominância absoluta, dominância relativa, frequência absoluta, frequência relativa e valor de importância relativo (MUELLER-DOMBOIS; ELLENBERG, 1974). Para o cálculo da diversidade florística e dominância das espécies, foram utilizados o índice de diversidade de Shannon $\left(\mathrm{H}^{\prime}\right)$ e o índice de equabilidade de Pielou (J') (BROWER; ZAR, 1984).

Foi comparada a composição florística estrutural da comunidade arbórea através da Análise de Correspondência Distendida (DCA) por meio da ordenaç̧ão das parcelas, utilizando a densidade das espécies com mais de cinco indivíduos, as quais passaram pela transformação logarítmica log $(x+1)$ para diminuir a discrepância entre os dados. 
A estrutura diamétrica foi calculada para toda a comunidade como também para as populações com valor de importância (VI) superior a 5\%, determinando as classes de DAP pelo método de Spiegel. O mesmo modelo foi utilizado para determinar os intervalos de classe (IC) na estrutura vertical (FELFILI; RESENDE, 2003). Para as classes diamétricas de todo o componente arbóreo foram realizados ajustes nas frequências, utilizando-se a equação de Meyer e realizado o cálculo do Quociente de Liocourt, de acordo com a metodologia de Schneider e Finger (2000).

As análises foram realizadas no software estatístico R (R DEVELOPMENT CORE TEAM, 2017), utilizando o pacote Vegan (OKSANEN, 2017).

\section{RESULTADOS E DISCUSSÃO}

A suficiência amostral representada pela curva de acumulação de espécies tendeu à estabilidade quando o ingresso de novas espécies não interferiu mais na representação florística. Assim, a amostragem foi adequada na área, uma vez que com a inclusão da última parcela obteve-se um aumento de 2,39 do número de espécie, a qual representou 3,62\% das espécies amostradas (Figura 2).

Figura 2 - Curva de acumulação de espécies da comunidade arbórea em um trecho de vegetação secundária de Floresta Estacional Decidual, RS

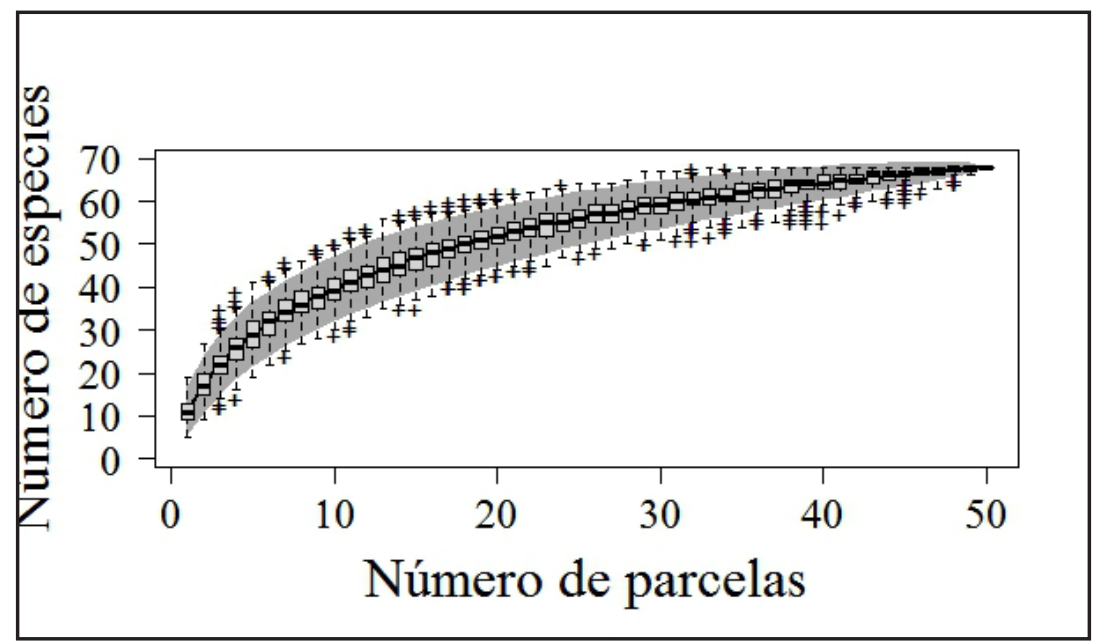

Fonte: Autores (2020) 
Os estimadores de riqueza Jackknife de primeira e segunda ordem, para o total de espécies, representaram a riqueza estimada e potencial da amostragem, respectivamente de $72,37 \%$ e 78,74 \%, o que correspondeu a 91 e 83 espécies. Esse valor foi suficiente para demonstrar que $70 \%$ de todas as espécies amostradas podem ser estimadas para o trecho florestal. Do mesmo modo que a diferença entre a riqueza estimada e potencial reflete nas mudanças da vegetação devido à ação antrópica.

Considerando-se sete espécies exóticas, além de uma pteridófita, foram identificadas 65 espécies arbóreas e arbustivas, distribuídas em 31 famílias botânicas com 2.045 indivíduos de DAP $\geq 5 \mathrm{~cm}$ (Tabela 1). Dentre as espécies arbóreas, dois indivíduos não foram identificados por inexistência de material vegetativo no período do levantamento e identificação da vegetação.

Tabela 1 - Composição florística amostrada em um trecho de Floresta Estacional Decidual, em ordem decrescente do Valor de importância para cada espécie, RS

\begin{tabular}{|c|c|c|c|c|c|c|c|c|}
\hline Espécie & Família & DA & DR & DoA & DoR & FA & FR & VI \\
\hline Casearia sylvestris Sw. & Salicaceae ${ }^{1}$ & 505 & 24,69 & 2,90 & 8,70 & 98 & 8,73 & 14,04 \\
\hline Nectandra lanceolata Nees & Lauraceae $^{1}$ & 170 & 8,31 & 8,14 & 24,39 & 66 & 5,88 & 12,86 \\
\hline Cupania vernalis Cambess. & Sapindaceae $^{1}$ & 293 & 14,33 & 2,07 & 6,21 & 92 & 8,20 & 9,58 \\
\hline Guarea macrophylla Vahl & Meliaceae ${ }^{1}$ & 195 & 9,54 & 1,74 & 5,21 & 80 & 7,13 & 7,29 \\
\hline Hovenia dulcis Thunb. & Rhamnaceae ${ }^{2}$ & 85 & 4,16 & 3,27 & 9,80 & 54 & 4,81 & 6,26 \\
\hline Ocotea puberula (Rich.) Nees & Lauraceae $^{1}$ & 51 & 2,49 & 2,75 & 8,25 & 50 & 4,46 & 5,07 \\
\hline $\begin{array}{l}\text { Cabralea canjerana (Vell.) } \\
\text { Mart. }\end{array}$ & Meliaceae $^{1}$ & 48 & 2,35 & 1,38 & 4,14 & 44 & 3,92 & 3,47 \\
\hline Matayba elaeagnoides Radlk. & Sapindaceae ${ }^{1}$ & 76 & 3,72 & 0,69 & 2,07 & 40 & 3,57 & 3,12 \\
\hline $\begin{array}{l}\text { Machaerium paraguariensis } \\
\text { Hassl. }\end{array}$ & Fabaceae $^{1}$ & 76 & 3,72 & 0,48 & 1,44 & 46 & 4,10 & 3,09 \\
\hline $\begin{array}{l}\text { Nectandra megapotamica } \\
\text { (Spreng.) Mez }\end{array}$ & Lauraceae $^{1}$ & 27 & 1,32 & 1,61 & 4,82 & 28 & 2,50 & 2,88 \\
\hline $\begin{array}{l}\text { Allophylus edulis (A. St-Hil. et } \\
\text { al.) Hieron. ex Niederl. }\end{array}$ & Sapindaceae $^{1}$ & 59 & 2,89 & 0,40 & 1,20 & 42 & 3,74 & 2,61 \\
\hline Cedrela fissilisVell. & Meliaceae $^{1}$ & 36 & 1,76 & 0,77 & 2,30 & 32 & 2,85 & 2,30 \\
\hline $\begin{array}{l}\text { Apuleia leiocarpa (Vogel) J. F. } \\
\text { Macbr. }\end{array}$ & Fabaceae $^{1}$ & 44 & 2,15 & 0,49 & 1,47 & 36 & 3,21 & 2,28 \\
\hline Inga marginata Willd. & Fabaceae $^{1}$ & 47 & 2,30 & 0,46 & 1,38 & 34 & 3,03 & 2,24 \\
\hline $\begin{array}{l}\text { Ficus luschnathiana (Miq.) } \\
\text { Miq. }\end{array}$ & Moraceae $^{1}$ & 12 & 0,59 & 1,03 & 3,07 & 10 & 0,89 & 1,52 \\
\hline
\end{tabular}


Tabela 1 - Continuação

\begin{tabular}{|c|c|c|c|c|c|c|c|c|}
\hline Espécie & Família & DA & DR & DoA & DoR & FA & FR & VI \\
\hline Cordia ecalyculata Vell. & Boraginaceae $^{1}$ & 17 & 0,83 & 0,27 & 0,80 & 22 & 1,96 & 1,20 \\
\hline $\begin{array}{l}\text { Actinostemon concolor } \\
\text { (Spreng.) Müll. Arg. }\end{array}$ & Euphorbiaceae $^{1}$ & 17 & 0,83 & 0,05 & 0,14 & 28 & 2,50 & 1,16 \\
\hline Casearia decandra Jacq. & Salicaceae $^{1}$ & 13 & 0,64 & 0,54 & 1,62 & 10 & 0,89 & 1,05 \\
\hline $\begin{array}{l}\text { Cordia trichotoma (Vell.) } \\
\text { Arráb. exSteud. }\end{array}$ & Boraginaceae $^{1}$ & 14 & 0,68 & 0,28 & 0,85 & 18 & 1,60 & 1,05 \\
\hline $\begin{array}{l}\text { Dalbergia frutescens (Vell.) } \\
\text { Britton }\end{array}$ & Fabaceae $^{1}$ & 16 & 0,78 & 0,06 & 0,19 & 18 & 1,60 & 0,86 \\
\hline $\begin{array}{l}\text { Annona neosalicifolia } \mathrm{H} \text {. } \\
\text { Rainer }\end{array}$ & Annonaceae ${ }^{1}$ & 10 & 0,49 & 0,16 & 0,48 & 16 & 1,43 & 0,80 \\
\hline Ficus sp. & Moraceae $^{1}$ & 5 & 0,24 & 0,65 & 1,96 & 2 & 0,18 & 0,80 \\
\hline Zanthoxylum rhoifolium Lam. & Rutaceae $^{1}$ & 10 & 0,49 & 0,15 & 0,44 & 16 & 1,43 & 0,78 \\
\hline Diospyros inconstans Jacq. & Ebenaceae $^{1}$ & 11 & 0,54 & 0,04 & 0,13 & 16 & 1,43 & 0,70 \\
\hline $\begin{array}{l}\text { Campomanesia xanthocarpa } \\
\text { (Mart.) O. Berg. }\end{array}$ & Myrtaceae $^{1}$ & 13 & 0,64 & 0,09 & 0,28 & 12 & 1,07 & 0,66 \\
\hline Banara tomentosa Clos & Salicaceae $^{1}$ & 12 & 0,59 & 0,04 & 0,12 & 14 & 1,25 & 0,65 \\
\hline Alsophila setosa Kaulf. & Cyatheaceae $^{1}$ & 2 & 0,10 & 0,49 & 1,47 & 4 & 0,36 & 0,64 \\
\hline $\begin{array}{l}\text { Luehea divaricata Mart. \& } \\
\text { Zucc. }\end{array}$ & Malvaceae $^{1}$ & 16 & 0,78 & 0,19 & 0,58 & 6 & 0,53 & 0,63 \\
\hline Aiouea saligna Meisn. & Lauraceae $^{1}$ & 9 & 0,44 & 0,23 & 0,69 & 8 & 0,71 & 0,61 \\
\hline $\begin{array}{l}\text { Campomanesia guazumifolia } \\
\text { (Cambess.) O. Berg. }\end{array}$ & Myrtaceae $^{1}$ & 12 & 0,59 & 0,05 & 0,15 & 12 & 1,07 & 0,60 \\
\hline $\begin{array}{l}\text { Parapiptadenia rígida } \\
\text { (Benth.) Brenan }\end{array}$ & Fabaceae $^{1}$ & 16 & 0,78 & 0,14 & 0,41 & 6 & 0,53 & 0,58 \\
\hline $\begin{array}{l}\text { Myrocarpus frondosus } \\
\text { Allemão }\end{array}$ & Fabaceae $^{1}$ & 9 & 0,44 & 0,11 & 0,34 & 10 & 0,89 & 0,56 \\
\hline $\begin{array}{l}\text { Zanthoxylum petiolare A. St. } \\
\text {-Hill. \& Tul. }\end{array}$ & Rutaceae $^{1}$ & 9 & 0,44 & 0,04 & 0,12 & 10 & 0,89 & 0,48 \\
\hline $\begin{array}{l}\text { Sorocea bonplandii (Baill.) W. } \\
\text { C. Burger et al. }\end{array}$ & Moraceae $^{1}$ & 6 & 0,29 & 0,02 & 0,07 & 12 & 1,07 & 0,48 \\
\hline Erythrina falcata Benth. & Fabaceae $^{1}$ & 5 & 0,24 & 0,23 & 0,70 & 4 & 0,36 & 0,43 \\
\hline $\begin{array}{l}\text { Syagrus romanzoffiana } \\
\text { (Cham.) Glassman }\end{array}$ & Arecaceae $^{1}$ & 5 & 0,24 & 0,05 & 0,15 & 10 & 0,89 & 0,43 \\
\hline Phytolacca dioica L. & Phytolaccaceae $^{1}$ & 5 & 0,24 & 0,20 & 0,60 & 4 & 0,36 & 0,40 \\
\hline Eugenia involucrata DC. & Myrtaceae $^{1}$ & 7 & 0,34 & 0,04 & 0,12 & 8 & 0,71 & 0,39 \\
\hline $\begin{array}{l}\text { Tecomastans (L.) Juss. ex. } \\
\text { Kunth }\end{array}$ & Bignoniaceae $^{2}$ & 4 & 0,20 & 0,05 & 0,16 & 8 & 0,71 & 0,36 \\
\hline \multicolumn{9}{|l|}{ Enterolobium } \\
\hline $\begin{array}{l}\text { contortisiliquum (Vell.) } \\
\text { Morong. }\end{array}$ & Fabaceae $^{1}$ & 7 & 0,34 & 0,12 & 0,36 & 4 & 0,36 & 0,35 \\
\hline
\end{tabular}


Tabela 1 - Conclusão

\begin{tabular}{|c|c|c|c|c|c|c|c|c|}
\hline Espécie & Família & DA & DR & DoA & DoR & FA & FR & VI \\
\hline $\begin{array}{l}\text { Albizia niopoides (Spruce ex } \\
\text { Benth) Burkart }\end{array}$ & Fabaceae $^{1}$ & 4 & 0,20 & 0,03 & 0,08 & 8 & 0,71 & 0,33 \\
\hline Melia azedarach L. & Meliaceae $^{2}$ & 3 & 0,15 & 0,10 & 0,29 & 6 & 0,53 & 0,33 \\
\hline $\begin{array}{l}\text { Lonchocarpus cf. nitidus } \\
\text { (Vogel) Benth. }\end{array}$ & Fabaceae $^{1}$ & 7 & 0,34 & 0,02 & 0,07 & 6 & 0,53 & 0,32 \\
\hline Pisonia zapallo Griseb. & Nyctaginaceae $^{1}$ & 4 & 0,20 & 0,12 & 0,35 & 4 & 0,36 & 0,30 \\
\hline Prunus myrtifolia (L.) Urb. & Rosaceae $^{1}$ & 3 & 0,15 & 0,06 & 0,17 & 6 & 0,53 & 0,28 \\
\hline Jacaranda micranta Cham. & Bignoniaceae $^{1}$ & 5 & 0,24 & 0,13 & 0,38 & 2 & 0,18 & 0,27 \\
\hline $\begin{array}{l}\text { Eriobotrya japônica (Thunb.) } \\
\text { Lindl. }\end{array}$ & Rosaceae $^{2}$ & 4 & 0,20 & 0,02 & 0,07 & 6 & 0,53 & 0,27 \\
\hline Morus sp. & Moraceae $^{2}$ & 4 & 0,20 & 0,02 & 0,07 & 6 & 0,53 & 0,27 \\
\hline Picrasma crenata (Vell.) Engl. & Simaroubaceae $^{1}$ & 5 & 0,24 & 0,06 & 0,18 & 4 & 0,36 & 0,26 \\
\hline Psidium guajava L. & Myrtaceae ${ }^{2}$ & 3 & 0,15 & 0,05 & 0,14 & 4 & 0,36 & 0,21 \\
\hline Bauhinia forficata Link & Fabaceae $^{1}$ & 3 & 0,15 & 0,04 & 0,13 & 4 & 0,36 & 0,21 \\
\hline Boehmeria caudata Sw. & Urticaceae $^{1}$ & 3 & 0,15 & 0,01 & 0,04 & 4 & 0,36 & 0,18 \\
\hline $\begin{array}{l}\text { Myrsine coriacea (Sw.) R. Br. } \\
\text { ex Roem. \& Schult. }\end{array}$ & Primulaceae $^{1}$ & 3 & 0,15 & 0,01 & 0,02 & 4 & 0,36 & 0,18 \\
\hline Citrus $x$ limonia(L.) Osbeck & Rutaceae $^{2}$ & 2 & 0,10 & 0,01 & 0,03 & 4 & 0,36 & 0,16 \\
\hline $\mathrm{NI}$ & $\mathrm{NI}$ & 2 & 0,10 & 0,01 & 0,02 & 4 & 0,36 & 0,16 \\
\hline $\begin{array}{l}\text { Chrysophyllum gonocarpum } \\
\text { (Mart. \& Eichlerex Miq.) }\end{array}$ & Sapotaceae $^{1}$ & 2 & 0,10 & 0,07 & 0,20 & 2 & 0,18 & 0,16 \\
\hline Ilex brevicuspis Reissek & Aquifoliaceae $^{1}$ & 3 & 0,15 & 0,03 & 0,08 & 2 & 0,18 & 0,14 \\
\hline $\begin{array}{l}\text { Mollinedia schottiana } \\
\text { (Spreng.) Perkins }\end{array}$ & Nyctaginaceae $^{1}$ & 1 & 0,05 & 0,05 & 0,15 & 2 & 0,18 & 0,13 \\
\hline $\begin{array}{l}\text { Citronela paniculata (Mart.) } \\
\text { R. A. Howard }\end{array}$ & Cardiopteridaceae $^{1}$ & 3 & 0,15 & 0,02 & 0,05 & 2 & 0,18 & 0,12 \\
\hline Ruprechtia laxiflora Meisn. & Polygonaceae $^{1}$ & 2 & 0,10 & 0,01 & 0,04 & 2 & 0,18 & 0,11 \\
\hline $\begin{array}{l}\text { Gymnanthes klotzschiana } \\
\text { Müll. Arg. }\end{array}$ & Euphorbiaceae $^{1}$ & 1 & 0,05 & 0,02 & 0,06 & 2 & 0,18 & 0,09 \\
\hline $\begin{array}{l}\text { Alchornea triplinervia } \\
\text { (Spreng.) Müll. Arg. }\end{array}$ & Euphorbiaceae $^{1}$ & 1 & 0,05 & 0,00 & 0,01 & 2 & 0,18 & 0,08 \\
\hline $\begin{array}{l}\text { Solanunsanctae-catharinae } \\
\text { Dunal }\end{array}$ & Solanaceae $^{1}$ & 1 & 0,05 & 0,00 & 0,01 & 2 & 0,18 & 0,08 \\
\hline Piper amalago L. & Piperacaceae $^{1}$ & 1 & 0,05 & 0,00 & 0,01 & 2 & 0,18 & 0,08 \\
\hline Strychus brasiliensis Mart. & Loganiaceae $^{1}$ & 1 & 0,05 & 0,00 & 0,01 & 2 & 0,18 & 0,08 \\
\hline
\end{tabular}

Fonte: Autores (2020)

Em que: 1 = espécie nativa; 2 = espécie exótica; $\mathrm{DA}=$ densidade absoluta (ind.ha-1 ${ }^{-1}$ ); $\mathrm{DR}=$ densidade relativa (\%); DoA = dominância absoluta( $\mathrm{m}^{2} / \mathrm{ha}$ ); $\mathrm{DoR}=$ dominância relativa (\%); $F A$ = frequência absoluta (\%); FR = frequência relativa (\%); VI = valor de importância (\%). 
Resultados encontrados na região do rebordo do Planalto Meridional foram semelhantes ao estudo como em Callegaro, Araújo e Longhi (2014) e Almeida et al. (2015). Esses resultados indicam que essas áreas são possuidoras de grande riqueza florística e de diversidade de espécies arbóreas em FED, como observado na Tabela 1. As famílias de maior riqueza em espécies arbóreas nativas foram Fabaceae (11 espécies), Lauraceae (quatro espécies), Euphorbiaceae, Myrtaceae, Meliaceae, Moraceae, Salicaceae e Sapindaceae (três espécies). Esse resultado foi semelhante ao encontrado por Scipioni et al. (2011) e Fávero et al. (2015), descrevendo as mesmas famílias como as mais importantes em fragmento de Floresta Estacional Decidual da região. Destacando as espécies nativas com maior valor de importância Casearia sylvestris (14,04\%), Nectandra lanceolata (12,86\%), Cupania vernalis (9,58\%), Guarea macrophylla (7,29\%), Ocotea puberula (5,07\%), Cabralea canjerana (3,47\%), Matayba eleaegnaoides (3,12 \%) e Machaerium paraguariensis (3,09\%), as quais juntas somaram $71,75 \%$ do valor de importância (Tabela 1). Essas espécies estão distribuídas de forma homogênea na área, ocupando mais de 50\% das parcelas e somam um total de 70\% em área basal.

Vale ressaltar que muitas das espécies destacadas em importância, neste estudo, compõem referências na literatura como espécies-chave nas etapas da recuperação de áreas degradadas. As mesmas apresentam características ecológicas importantes, como a plasticidade fenotípica e a dispersão atrativa à fauna. Além de indicadoras de ambientes preferenciais, também são mantenedoras de serviços ambientais (MARCUZZO; ARAUJO; LONGHI, 2013; ATTANASIO, 2008).

As espécies com maior densidade relativa em número de indivíduos pela estrutura horizontal, - Casearia sylvestris (24,7\%), Cupania vernalis (14,3\%), Guarea macrophylla (9,5\%) e Nectandra lanceolata (8,3\%). Entre essas espécies, a maior dominância foi verificada para a espécie Nectandra lanceolata, ao passo que a espécie Casearia sylvestris apresentou o maior número de indivíduos amostrado com baixo valor em área basal. Segundo Longhi et al. (2000), isso deve-se em razão de muitos 
indivíduos da mesma espécie apresentarem baixos valores em diâmetro, como neste caso apresentando média de $8 \mathrm{~cm}$ em DAP, enquanto que Nectandra lanceolata apresentou valor de diâmetro médio de $12 \mathrm{~cm}$. Também se observou para a espécie Guarea macrophylla, em terceiro lugar na abundância de indivíduos, baixo valor de dominância $\left(1,74 \mathrm{~m}^{2} \mathrm{ha}^{-1}\right)$.

Para a espécie Guarea macrophylla, o que contribuiu para atingir o limite inferior de circunferência $(15,7 \mathrm{~cm})$ foi o seu formato de touceiras vindo da brotação após corte raso, gerando vários indivíduos múltiplos com bifurcação abaixo da altura do solo. Segundo Moro e Martins (2011), um indivíduo é considerado único quando representar uma estrutura acima do solo sem conexão com outra estrutura ao seu nível, caso contrário se dois indivíduos aparecerem ligados com uma base em comum são considerados um único indivíduo. Além disso, é possível afirmar que, por ser uma espécie seletiva higrófita (LORENZI, 2009), sua abundância está relacionada ao solo úmido no decorrer do trecho florestal, no qual foi possível observar as nascentes e um curso d'água que favoreceram a distribuição da espécie no local.

Já a espécie exótica Hovenia dulcis, amplamente distribuída na região Sul do Brasil, principalmente para fins madeireiros, está em quinto lugar no ranking de importância, considerando as 65 espécies encontradas na área, apresentando 85 indivíduos de dominância absoluta igual a 3,27 m²/ha-1 e média de DAP com $12 \mathrm{~cm}$. Salienta-se aqui a importância do monitoramento em relação à presença da exótica em áreas estacionais, uma vez que é considerada exótica invasora causadora de danos ambientais e, geralmente, áreas secundárias são mais suscetíveis à ocorrência da espécie.

A diversidade florística representada pelo índice de Shannon $\left(\mathrm{H}^{\prime}\right)$ apresentou valor de 2,91 nats.ind ${ }^{-1}$ e a dominância ecológica pela equabilidade de Pielou (J') foi de 0,69 . Esses valores podem ser considerados intermediários, quando comparados aos últimos estudos realizados em remanescentes de FED secundária, na região central do estado (Tabela 2). Vale lembrar que o valor de Shannon $\left(\mathrm{H}^{\prime}\right)$ geralmente varia entre 1,5 e 3,5, podendo chegar até 4,5 em florestas tropicais (FELFILI; REZENDE, 2003). 
Nesse sentido, na comunidade arbórea em geral há uma grande diferença em abundância de indivíduos, sendo verificada a dominância de poucas espécies e baixa diversidade. Isso deve-se, provavelmente, pelo grau de antropização que ainda dificulta a estabilização de alguns grupos funcionais no componente arbóreo como, também, pela monodominância na comunidade vegetal. Ainda, a distribuição das espécies arbóreas mais representativas está condicionada, neste caso, a facilitação do ambiente, uma vez que o mesmo não atua como um filtro seletivo para as características ecológicas dessas espécies e supõe-se que as mesmas apresentam aptidão de alocarse em diferentes condições do trecho florestal (MISSIO; LONGHI, 2019).

Tabela 2 - Levantamentos Fitossociológicos em remanescentes de vegetação secundária de Floresta Estacional Decidual, RS

\begin{tabular}{|c|c|c|c|c|c|}
\hline Autores & Formação & Área & $\begin{array}{c}\text { Limite } \\
\text { de inclusão }\end{array}$ & $\mathbf{H}^{\prime}$ & $J^{\prime}$ \\
\hline Budke et al. (2004) & FED* & 1 ha & $\mathrm{DAP}>5$ & 2,73 nats. ind $^{-1}$ & 0,69 \\
\hline Kilka e Longhi (2011) & FED & $\begin{array}{l}3 \text { áreas } \\
=3 \text { ha }\end{array}$ & $\mathrm{DAP}>10 \mathrm{~cm}$ & $\begin{array}{c}2,816 \text { a } \\
\text { 3,338 nats.ind-1 }\end{array}$ & - \\
\hline Marcuzzo, Araujo e Longhi (2013) & FED & 0,24 ha & $\mathrm{DAP}>5$ & 3,0 nats. ind ${ }^{-1}$ & 0,78 \\
\hline Callegaro, Araújo e Longhi (2014) & FED & 1,32 ha & $\mathrm{DAP}>5$ & 3,58 nats. ind $^{-1}$ & 0,83 \\
\hline
\end{tabular}

Fonte: Autores (2020)

Em que: $\mathrm{H}^{\prime}$ = índice de Shannon; J' = equabilidade de Pielou; FED = Floresta Estacional Decidual; *Aluvial.

Ao se analisar a ordenação produzida pela DCA (Figura 3), a qual apresenta a distância das parcelas de acordo com a variação das espécies distribuídas ao longo da comunidade (FELFILI et al., 2011), demonstrou-se divisões fracas para os dois primeiros eixos da ordenação $(0,2000$ e 0,1769, respectivamente), considerando que para florestas heterogêneas o autovalor significativo seja >0,3 (FELFILI et al., 2007). As parcelas estão agrupadas no eixo central da ordenação, indicando uma área mais homogênea com baixa substituição florística, apontando que há variação na abundância das espécies entre as parcelas, mas o gradiente é curto. Durante os trabalhos de campo, para esse caso, verificou-se que a extensão em largura da área pode ser o indicativo dessa 
baixa heterogeneidade. No entanto, foi observado o ingresso de novas espécies na área como Trichilia elegans e Dasyphyllum spinescens que irão interagir com as demais espécies na dinâmica do estrato arbóreo e aumentar a diversidade florística.

Figura 3 - Ordenação produzida pela Análise de Correspondência Distendida das 50 parcelas (círculos fechados em negrito) distribuídas em 1 ha de vegetação secundária em Floresta Estacional Decidual, RS

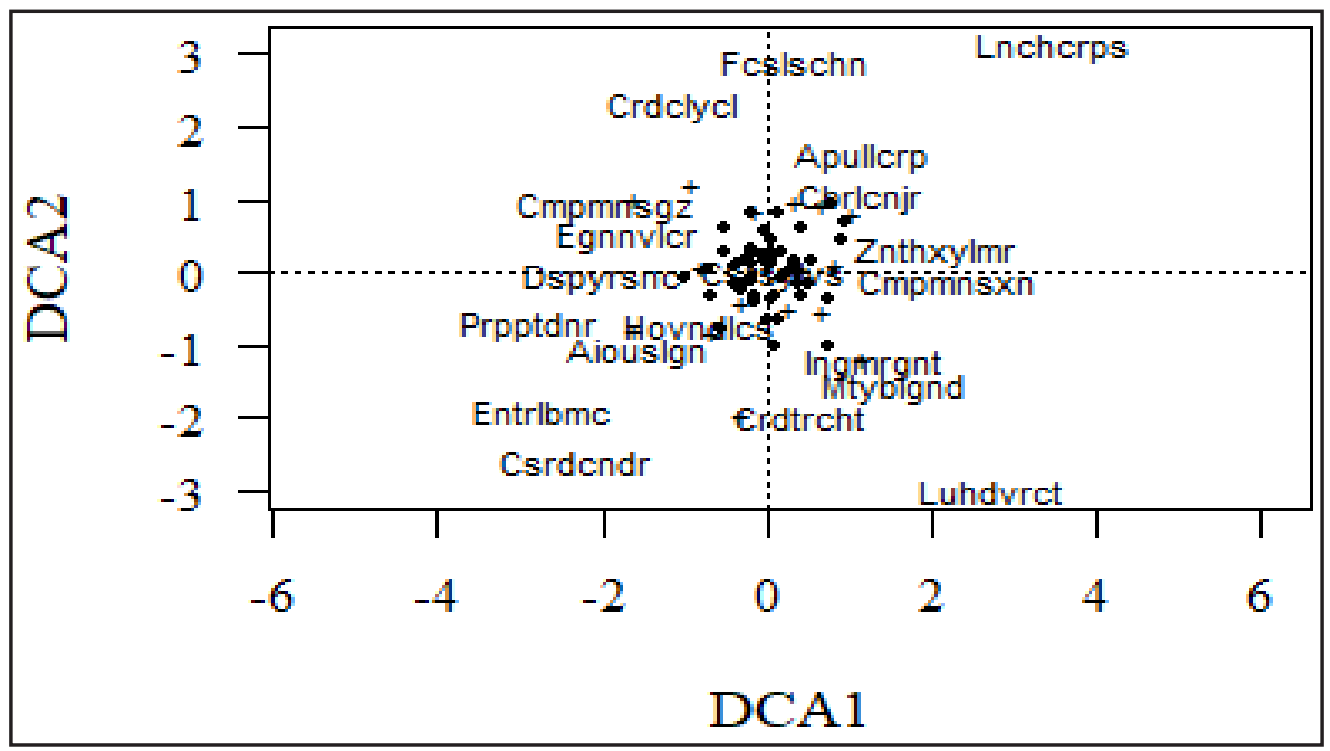

Fonte: Autores (2020)

Em que: Ingmrgn = Inga marginata; Mtyblgnd = Matayba elaeagnoides; Crdtrcht = Cordia trichotoma;Allphyls = Allophylus edulis; Apullcrp =Apuleia leiocarpa; $\mathrm{Cbrlcnjrn}$ = Cabralea canjerana; Fcslschn = Ficus luschnathiana; Crdclycl = Cordia ecalyculata; Csrdcndr = Casearia decandra; Cmpmnsgs = Campomanesia guazumifolia; Dspyrsnc = Diospyros inconstans; Znthxylm = Zanthoxylum rhoifolium; Csrsylvs = Casearia sylvestris; $\mathrm{Cmpmnsxn}=$ Campomanesia xanthocarpa; Lhdvrct $=$ Luehea divaricata; Aiouslgn = Aioueasaligna; Prpptdnr = Parapiptadenia rígida; Hovndlcs = Hovenia dulcis; Campomanesia guazumifolia; Eugnnvlc = Eugenia involucrata; Entrlbmc = Enterolobium corticilicum; Lnchcrps = Lonchocarpus nitidus. Demais espécies estão representadas pelo símbolo "+".

A análise da distribuição diamétrica (Figura 4) representou o comportamento esperado para a comunidade com tendência à curva exponencial negativa, e o incremento diamétrico em classes foi confirmado pelo coeficiente de determinação ( $R^{2}$ =0,964365). Assim, pela análise foi possível identificar a capacidade autorregenerativa 
da comunidade arbórea, e através da menor frequência dos indivíduos com elevado DAP, isto é, há um elevado número de indivíduos jovens ocupando as primeiras classes de frequência. De acordo com o quociente de Liocourt, cujo valor foi de 2,03, a comunidade, de um modo geral, apresentou equilíbrio entre as taxas demográficas, no entanto, a fase de recrutamento de algumas espécies pode vir a ser prejudicada pelo histórico de perturbação, como já observado em outros estudos em florestas tropicais (GOMES; SOUSA; MEIRA NETO, 2004; CARVALHO; NASCIMENTO, 2009).

Figura 4 - Distribuição diamétrica da comunidade arbórea pertencente à vegetação secundária em um trecho de Floresta Estacional Decidual, RS

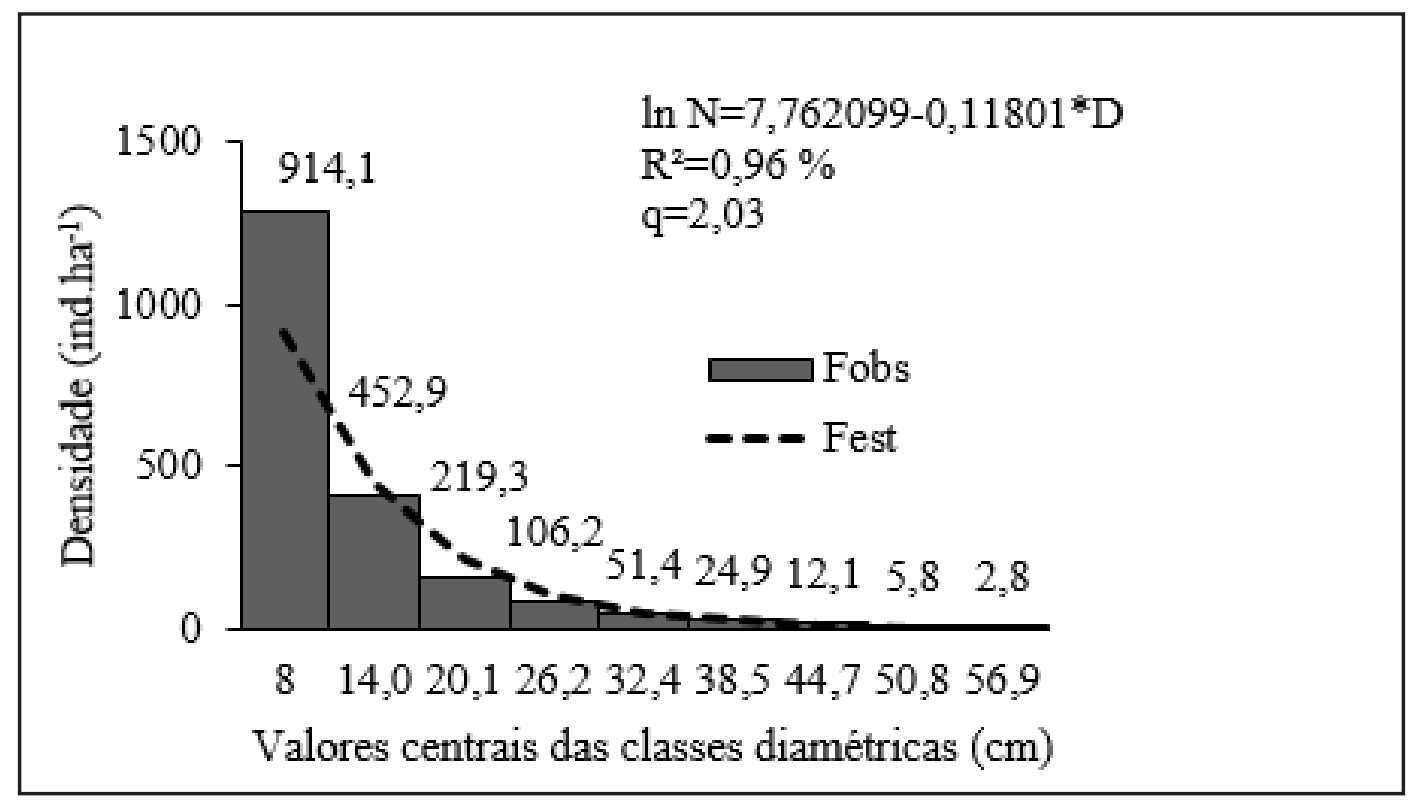

Fonte: Autores (2020)

Pelo histograma de frequência (Figura 5), há uma maior abundância de espécies concentradas nas classes de menor altura $(90,52 \%)$ e poucos indivíduos emergentes. É possível inferir na formação de um dossel de estrato superior esparso e um estrato intermediário contínuo, sendo uma característica da floresta em estágio intermediário de recomposição, em que a cobertura arbórea varia de aberta a fechada de acordo com Conama (BRASIL, 1994). Em um estudo realizado por Hack et al. (2005), também em FED, a maioria dos indivíduos estiveram entre os estratos intermediário e superior 
da floresta, sendo possível considerar o fragmento em estágio avançado de sucessão. Contudo, o mesmo apresentou poucas espécies no estrato inferior devido à presença de gado na área. A presença de gado não foi observada como fator antrópico, visto que a mesma apresenta, em toda sua extensão, proteção com cerca.

Figura 5 - Distribuição vertical da comunidade arbórea pertencente à vegetação secundária em um trecho de Floresta Estacional Decidual, RS

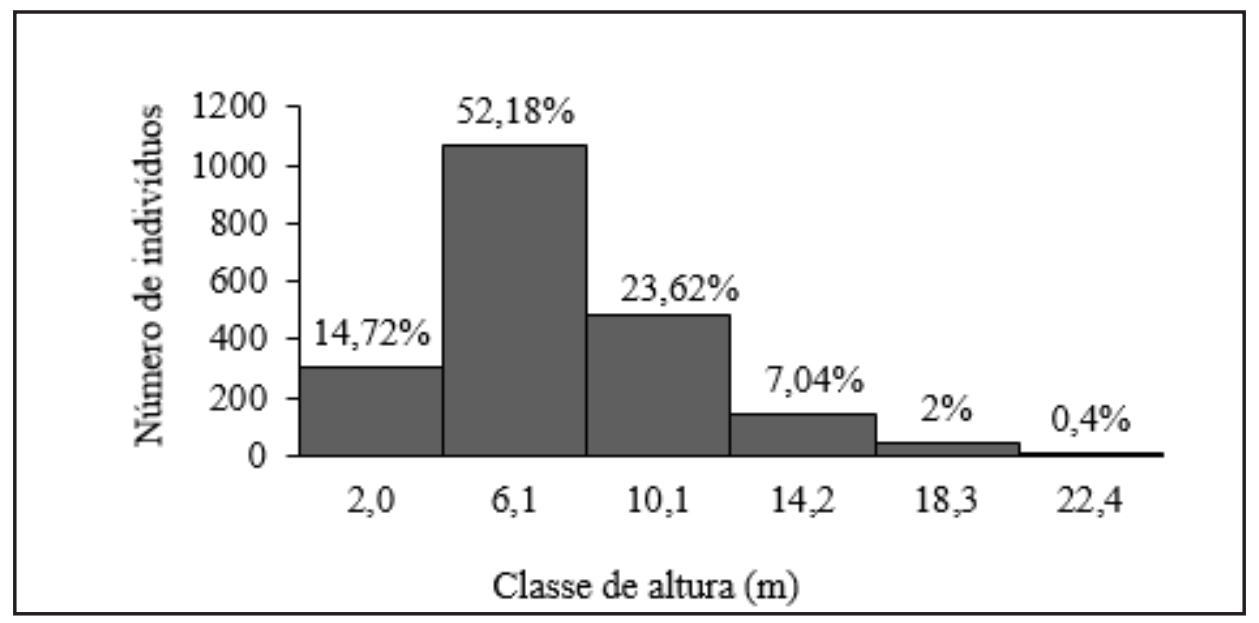

Fonte: Autores (2020)

Das espécies arbóreas nativas acima de 5\% em VI, apenas Nectandra lanceolata e Ocotea puberula não apresentaram modelo J-invertido (Figura 6). A primeira espécie apresentou maior concentração na segunda, terceira e quarta classe diamétrica (35,47 e 28 indivíduos). Já Ocotea puberula apresentou a maioria dos indivíduos concentrados nas classes de DAP com até $20 \mathrm{~cm}$, sendo a terceira classe com 33\% da população.

Pode-se inferir que para essas duas espécies há um desequilíbrio na dinâmica das populações, principalmente na fase de recrutamento (VACCARO et al., 1999), possivelmente pela substituição dessas espécies iniciais por outras espécies tardias. Também, o comportamento heliófilo pode estar sendo prejudicado pelo fechamento de dossel, ou problemas com a regeneração relacionada à fauna dispersora. Do mesmo modo, as variações ambientais, histórico de perturbação e as características ecológicas podem formar um conjunto de restrições para a composição e dinâmica dessas espécies na comunidade, as quais diretamente estão relacionadas com as fases de sucessão na floresta, bem como com a organização florística e estrutural. 
Figura 6 - Distribuição diamétrica das populações de espécies arbóreas nativas com valor acima de 5\% em VI, amostradas na vegetação secundária em um trecho de Floresta Estacional Decidual, RS

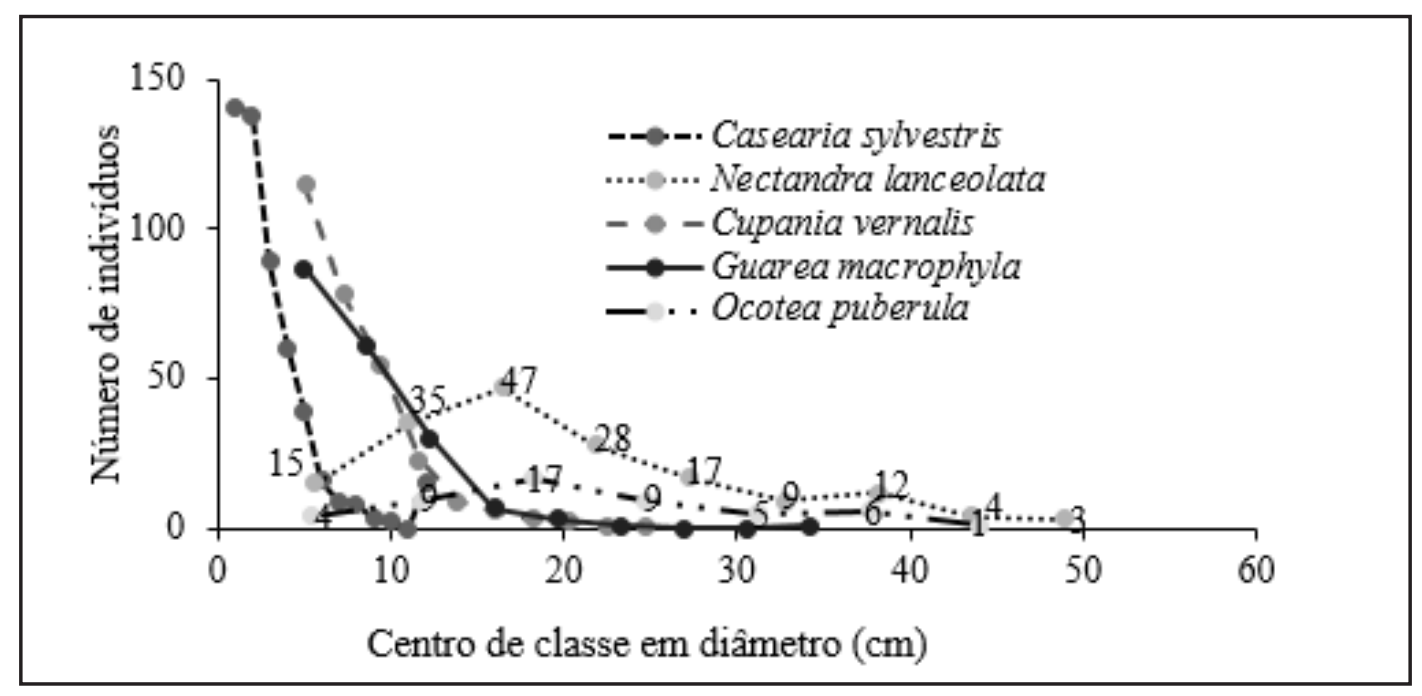

Fonte: Autores (2020)

Como observado, a presença do maior número de indivíduos jovens reflete a capacidade de regeneração da área após distúrbio, o que presume o potencial de resiliência do trecho florestal. Além disso, mesmo a área com histórico de antropização e presença de espécies exóticas, estabeleceu-se em maior número com as características fisionômicas da Floresta Estacional Decidual, quando comparada a outros levantamentos arbóreos da região Sul do Brasil (CALLEGARO; ARAÚJO; LONGHI, 2014; ALMEIDA et al., 2015). Isso deve-se pela conectividade com outros remanescentes, os quais contribuem com a fonte de propágulos e o próprio banco de sementes do solo (MARTINS, 2012), como, também, a heterogeneidade ambiental. Esta última, como já observado em outros estudos (SCHUMACHER et al., 2011; MARCUZZO; ARAUJO; LONGHI, 2012), sendo inclusiva no estabelecimento e distribuição de determinados grupos de plantas e na adaptação de outras às condições naturais, caracterizando, dessa forma, o mosaico vegetacional da sucessão secundária nas áreas antropizadas da Floresta Estacional Decidual. 


\section{CONCLUSÕES}

Pela caracterização florística e estrutural da comunidade arbórea foi possível diagnosticar o padrão de desenvolvimento da floresta, após distúrbio antrópico, sendo o trecho florestal resiliente a tal fator.

A maioria dos indivíduos arbóreos amostrados está localizada na classe de menores diâmetros e menores alturas, indicando as flutuações e estabilidade das espécies, na sucessão ecológica, de uma floresta em estágio intermediário de regeneração.

A composição florística está representada pela maioria das espécies características da fisionomia da Floresta Estacional Decidual, mesmo com a presença de espécies exóticas.

Todavia, a presença de Hovenia dulcis demonstrou seu estabelecimento e desenvolvimento na área com grande participação na comunidade arbórea verificado pelo valor de importância, sendo um fator preocupante para a ocorrência das nativas.

\section{AGRADECIMENTOS}

À CAPES pela concessão da bolsa de doutorado ao primeiro autor.

\section{REFERÊNCIAS}

ALMEIDA, C. M. et al. Análise de agrupamentos em remanescente de Floresta Estacional Decidual. Ciência Florestal, Santa Maria, v. 25, n. 3, p. 781-789, 2015.

ANGIOSPERM PHYLOGENY GROUP IV. An update of the Angiosperm phylogeny group classification for the orders and families of flowering plants. Botanical Journal of the Linnean Society, London, v. 181, p. 1-20, 2016.

ATTANASIO, C. M. Manual Técnico. Restauração e monitoramento da Mata Ciliar e da Reserva Legal para a Certificação Agrícola - Conservação da Biodiversidade na Cafeicultura. Piracicaba: IMAFLORA, 2008. $60 \mathrm{p}$.

BRASIL. Ministério do Meio Ambiente. Resolução do Conama n. 33, de 7 de dezembro de 1944. Define estágios sucessionais das formações vegetais que ocorrem na região da Mata Atlântica do Estado do Rio Grande do Sul, visando viabilizar critérios, normas e procedimento para o manejo, utilização racional e conservação da vegetação natural. Diário Oficial da União, Brasília, DF, n. 248, p. 21352-21353, 1994. 
BROWER, J. E.; ZAR, J. H. Field and laboratory methods for general ecology. Duduque: W.M.C. Brow, 1984. 84 p.

BUDKE, J. C. et al. Florística e fitossociologia do componente arbóreo de uma floresta ribeirinha, arroio Passo das Tropas, Santa Maria, RS, Brasil. Acta Botanica Brasilica, Belo Horizonte, v. 18, n. 3, p. 581-589, 2004.

BURNHAM, K. P.; OVERTON, W. S. Estimation of the size of a closed population when capture probabilities vary among animals. Ecology, London, n. 65, p. 927-936, 1978.

CALLEGARO, R. M.; ARAÚJO, M.; LONGHI, S. J. Fitossociologia de agrupamentos em Floresta Estacional Decidual no Parque Estadual Quarta Colônia, Agudo-RS. Agrária, Recife, v. 9, n. 4, p. 590-598, 2014.

CARVALHO, F. A.; NASCIMENTO, M. T. Estrutura diamétrica da comunidade das principais populações arbóreas de um remanescente de Floresta Atlântica Submontana (Silva Jardim-RJ, Brasil). Árvore, Viçosa, MG, v. 33, n. 2, p. 327-337, 2009.

COOK, J. E. Implications of modern successional theory for typing: a review. Forest Science, Knivista, v. 4, p. 67-75, 1996.

FÁVERO, A. A. et al. Distribuição de abundância de espécies da comunidade arbórea do topo de um morro na floresta estacional subtropical. Ciência Rural, Santa Maria, v. 45, n. 5, p. 806813, 2015.

FELFILI, J. M. et al. Análise multivariada em estudos de vegetação. Brasília: Departamento de Engenharia Florestal, Universidade de Brasília, 2007. (Comunicações Técnicas Florestais).

FELFILI, J. M. et al. Procedimentos e Métodos de Amostragem da Vegetação. In: FELFILI, J. M. et al. (ed.). Fitossociologia no Brasil: métodos e estudos de casos. Viçosa, MG: Ed. UFV, 2011. p. 87-121.

FELFILI, J. M.; REZENDE, R. P. Conceitos e métodos em fitossociologia. Brasília: UNB, 2003. $68 \mathrm{p}$.

GANDOLFI, S.; MARTINS, S. V.; RODRIGUES, R. R. Forest restoration: many views and objectives. In: RODRIGUES, R. R.; MARTINS, S. V.; GANDOLFI, S. (ed.). Hight diversity forest restoration in degraded areas: methods and projects in Brazil. New York: Nova Science, 2007. p. 3-26.

GASTAUER, M.; MEIRA-NETO, J. A. A. A multifacetada diversidade biológica e suas medições. In: EISENJOHR, P. V. et al. (ed.). Fitossociologia no Brasil: métodos e estudos de casos. Viçosa, MG: Ed. UFV, 2015. p. 31-67.

GOMES, A. P. C.; SOUZA, A. L.; MEIRA NETO, J. A. Alteração estrutural de uma área florestal explorada convencionalmente na bacia do Paraíba do Sul, Minas Gerais, nos domínios de Floresta Atlântica. Árvore, Viçosa, MG, v. 28, n. 3, p. 407-417, 2004.

HACK, C. et al. Análise fitossociológica de um fragmento de Floresta Estacional Decidual no município de Jaguari, RS. Ciência Rural, Santa Maria, v. 35, n. 5, p. 1083-1091, 2005. 
HELTSHE, J.; FORRESTOR, N. E. Estimating species richness using the Jackknife procedure. Biometrics, Texas, n. 39, p. 1-11, 1983.

JARDIM BOTÂNICO DO RIO DE JANEIRO. Lista de Espécies da flora doo Brasil. Rio de Janeiro, 2016. Disponível em: www.floradobrasil.jbrj.gov.br. Acesso em: 25 ago. 2017.

KILCA, R. V.; LONGHI, S. J. A composição florística e a estrutura das florestas secundárias no rebordo do Planalto Meridional. In: SCHUMACHER, M. V. et al. (ed.). A Floresta Estacional Subtropical: caracterização e ecologia no rebordo do Planalto Meridional. Santa Maria: Pallotti, 2011. p. 53-83.

KÖPPEN, W. Das geographische System der Klimate. In: KÖPPEN, W.; GEIGER, R. (ed.). Handbuch der Klimatologie: Gebruder Borntrager. Berlin: [s. n.], 1936. 44 p.

LONGHI, S. J. et al. Aspectos fitossociológicos de fragmento de Floresta Estacional Decidual, Santa Maria, RS. Ciência Florestal, Santa Maria, v. 10, n. 2, p. 59-74, 2000.

LORENZI, H. Árvores brasileiras: manual de identificação e cultivo de plantas arbóreas nativas do Brasil. 1. ed. Nova Odessa: Instituto Plantarum, 2009. v. 3. 234 p.

LORENZI, H. et al. Frutas brasileiras e exóticas cultivadas (de consumo in natura). Nova Odessa: Instituto Plantarum de Estudos da Flora, 2006. 639 p.

MARCUZZO, S. B.; ARAUJO, M. M.; LONGHI, S. J. Estrutura e relações ambientais de grupos florísticos em fragmento de Floresta Estacional Subtropical. Revista Árvore, Viçosa, MG, v. 37, n. 2, p. 275-287, 2013.

MARTINS, S. M. Ecologia de florestas tropicais no Brasil. 2. ed. Viçosa, MG: Ed UFV, 2012. $371 \mathrm{p}$.

MISSIO, F. F.; LONGHI, S. J. Composição arbórea da floresta estacional decidual em relação a heterogeneidade ambiental no rebordo do planalto meridional, RS. Agrarian Academy, [s. I.], v. 6 , p. 15, 2019.

MORO, M. F.; MARTINS, F. R. Métodos de levantamento do componente arbóreo-arbustivo. In: FITOSSOCIOLOGIA no Brasil: métodos e estudos de casos. Viçosa, MG: Ed. UFV, 2011. p. 174212.

MUELLER-DOMBOIS, D.; ELLENBERG, H. Aims and of vegetation ecology. New York: John Wiley \& Sons, 1974. 547 p.

OKSANEN, J. et al. Vegan: community ecology package. R package version 2.4.1. [S. I.: s. n.], 2016. p. 4-278.

PEDRON, F. de A.; DALMOLIN, R. S. D. Solos da região do rebordo do Planalto Meridional no Rio Grande do Sul. In: SCHUMACHER, M. V. et al. (ed.). A Floresta Estacional Subtropical: caracterização e ecologia no rebordo do Planalto Meridional. Santa Maria: Pallotti, 2011. p. 33-51.

PEDRON, F. de A. et al. Principais solos da região da Quarta Colônia, Rio Grande do Sul. Santa Maria: Departamento de Solos - UFSM, 2007. 43 p. 
PICKETT, S. T. A.; OSTFELD, R. S. The shifting paradigm in ecology. In: KNIGHT, R. L.; BATES, S. F. (ed.). Anew century for natural resources management. Washington: Island Press, 1994. p. 261-278.

R DEVELOPMENT CORE TEAM. R: a language and environment for statistical computing. [S. I.]: R Foundation for Statistical Computing, 2017. Disponível em: http://www.R-project.org. Acesso em: 13 out. 2017.

SCHUMACHER, M. V. et al. A Floresta Estacional Subtropical: caracterização e ecologia no rebordo do Planalto Meridional. Santa Maria: Pallotti, 2011. 320 p.

SCIPIONI, M. C. et al. Análise dos padrões florísticos e estruturais da comunidade arbóreaarbustiva em gradientes de solo e relevo. In: SCHUMACHER, M. V. et al. (ed.). A Floresta Estacional Subtropical: caracterização e ecologia no rebordo do Planalto Meridional. Santa Maria: Pallotti, 2011. p. 85-103.

SOBRAL, M. et al. Flora arbórea e arborescente do Rio Grande do Sul, Brasil. 2. ed. São Carlos: RiMa, 2013. 357 p.

SCHNEIDER, P. R.; FINGER, C. A. G. Manejo sustentado de floresta inequiâneas heterogêneas. Santa Maria: UFSM, 2000. 195 p.

VACCARO, S. et al. Aspectos da composição florística e categorias sucessionais do estrato arbóreo de três subseres de uma Floresta Estacional Decidual, no município de Santa Tereza - RS. Ciência Florestal, Santa Maria, v. 9, p. 1-18, 1999.

\section{Contribuição de Autoria}

\section{1 - Francieli de Fátima Missio}

Engenheira Florestal, Dra.

https://orcid.org/0000-0002-0423-7756•francielimissio@gmail.com.br

Contribuição: Administração do projeto, Escrita - primeira redação, Escrita - revisão e edição

\section{2 - Solon Jonas Longhi}

Engenheiro Florestal, Dr., Professor

https://orcid.org/0000-0002-5701-2139•longhi.solon@gmail.com

Contribuição: Supervisão 


\section{3 - Matheus Degrandi Gazzola}

Engenheiro Florestal

https://orcid.org/0000-0001-9652-1895•matheus.d.gazzola@gmail.com

Contribuição: Metodologia

\section{4 - Marina Scheuer}

Engenheira Florestal

https://orcid.org/0000-0002-0929-301X•marina.scheuer@gmail.com

Contribuição: Metodologia

\section{5 - Rodrigo da Silva Pinto}

Engenheiro Florestal

https://orcid.org/0000-0001-5002-0649•silvarp.96@gmail.com

Contribuição: Metodologia

\section{6 - Lutero Lerner}

Engenheiro Florestal

https://orcid.org/0000-0001-5414-7102•luterolerner@hotamil.com

Contribuição: Metodologia

\section{7 - Diego Cella Cassol}

Engenheiro Florestal

https://orcid.org/0000-0002-2130-6856•diegocella86@hotmail.com

Contribuição: Metodologia

\section{8 - Gabriel Angostini Orso}

Engenheiro Florestal

https://orcid.org/0000-0001-5002-0649•gabrielorso16@gmail.com

Contribuição: Metodologia

\section{9 - Mauricio Stangarlin}

Engenheiro Florestal

https://orcid.org/0000-0002-0691-4677•mauriciostangarlin@hotmail.com Contribuição: Metodologia 


\section{Como citar este artigo}

Missio, F. F.; Longhi, S. J.; Gazzola, M. D.; Scheuer, M.; Pinto, R. S.; Lerner, L.; Cassol, D. C.; Orso, G. A.; Stangarlin, M. Caracterização florística e estrutural da vegetação arbórea em um trecho de Floresta Estacional Decidual, RS, Brasil. Ciência Florestal, Santa Maria, v. 31, n. 3, p. 1124-1146, 2021. DOI 10.5902/1980509831435. Disponível em: https://doi.org/10.5902/1980509831435. Acesso em: xx mês-abreviado 2021. 